\title{
Psychological Reactions in Women with Pregnancy Termination Due to Fetal Anomaly
}

\section{Gurcan TURKYILMAZ1, Yavuz Selim ATAN², Emircan ERTURK ${ }^{2}$, Sebnem TURKYILMAZ ${ }^{3}$}

Van, Turkey

\section{ABSTRACT}

OBJECTIVE: We aimed to determine and compare grief, depression, and post-traumatic stress scores in women who underwent termination of pregnancy due to fetal anomaly in the first vs. second-trimester of pregnancy.

STUDY DESIGN: Forty-three women who underwent termination of pregnancy for fetal anomaly were subdivided into two categories in this prospective-cohort study: First-trimester group, which was defined as termination of pregnancy performed $<14$ weeks of gestation, and Second-trimester termination of pregnancy who underwent termination of pregnancy between 20 and 28 weeks of pregnancy. Eight weeks after the termination of pregnancy, the Beck Depression Inventory, Perinatal Grief Scale-short version, and Impact of Event Scale-Revised were performed with face-to-face interviews.

RESULTS: Twenty-four women in the first-trimester group and 19 women in the second-trimester group were enrolled. The mean Beck Depression Inventory score was 7.3 \pm 4.2 in the first-trimester group and $11.1 \pm 4.6$ in the second-trimester group $(p=0.033)$. The mean Perinatal Grief Scale-short scores were $86.3 \pm 17.2$ and $101.4 \pm 29.2$ in the first and second-trimester groups, respectively $(p=0.014)$. Impact of Event Scale-Revised scores of the first trimester and second-trimester groups were $22.5 \pm 8.6$ and $35.3 \pm 17.1$, respectively $(p=0.022)$. Depression was detected in $29.1 \%$ of women in the first-trimester group and $57.8 \%$ in the second-trimester group $(p=0.023)$. Perinatal grief was significantly higher in the second-trimester group $(45.8 \%$ vs. $84.2 \% p<0.01)$. Post-traumatic stress was significantly higher in the second-trimester group $(41.6 \%$ vs. $73.6 \%, p=0.031)$.

CONCLUSION: Our study indicates that termination of pregnancy for fetal anomaly causes severe psychiatric problems in most women. Depression, grief, and post-traumatic stress are more prominent in women who underwent termination of pregnancy in the second trimester of pregnancy than in the first trimester.

Keywords: Anomaly, Depression, Grief, Stress, Termination

Gynecol Obstet Reprod Med 2021;27(3):202-206

${ }^{1}$ Department of Obstetrics and Gynecology, Maternal-Fetal Medicine Unit, Van Education and Research Hospital. Van, Turkey

${ }^{2}$ Department of Psychiatry, Yuzuncu Yil University, Faculty of Medicine. Van, Turkey

${ }^{3}$ Department of Obstetrics and Gynecology, Van Education and Research Hospital. Van, Turkey

Address of Correspondence: Gurcan Turkyilmaz Department of Obstetrics and Gynecology, Maternal-Fetal Medicine Unit, Van Education and Research Hospital, Van, Turkey gurcanturkyilmaz@gmail.com

Submitted for Publication: 24.08.2020 Revised for Publication: 04.02.2021 Accepted for Publication: 23.03.2021 Online Published: 31.03.2021

ORCID IDs of the authors: GT:0000-0002-5514-0233

YSA:0000-0003-0995-5287, EE:0000-0003-0169-6903 ST:0000-0002-3984-5663

\begin{tabular}{|c|c}
\hline $\begin{array}{c}\text { Quick Response Code: } \\
\text { and }\end{array}$ & Access this article online \\
\cline { 2 - 2 } & $\begin{array}{l}\text { Website: www.gorm.com.tr } \\
\text { e- mail: info@gorm.com.tr }\end{array}$ \\
\cline { 2 - 2 } & DOI:10.21613/GORM.2021.1145 \\
\hline
\end{tabular}

How to cite this article: Turkyilmaz G. Atan YS. Erturk E. Turkyilmaz S Psychological Reactions in Women with Pregnancy Termination Due to Fetal Anomaly Gynecol Obstet Reprod Med. 2021;27(3):202-206

\section{Introduction}

In recent years, the prenatal diagnosis of fetal anomalies increased dramatically due to improvement in imaging techniques. For many couples, detecting a fetal anomaly is an unexpected and devastating event, causing severe emotional harm to women. Since most fetal abnormalities lead to severe morbidity and mortality, families experience the dilemma of continuing the pregnancy or termination of pregnancy (TOP). In our country, the government permits TOP if the child will be born likely severely disabled or die due to detected anomaly. Also, there is no specific gestational week limitation for TOP (1).

In the first trimester, mothers have not experienced fetal movements, and the relationship with the baby is shorter than in the second trimester. After 20 weeks of gestation, many women may feel the fetal movements and the maternal-fetal attachment is more reliable than the first trimester of pregnancy. Negative feelings such as guilt, self-blame, and shame 
can be seen in women who underwent TOP after detected fetal anomaly.

First-trimester TOP is associated with less maternal morbidity than the second-trimester TOP (2). Most studies suggest that induced abortion for a maternal request before ten weeks of gestation is not associated with an increased risk of mental health disorders (3). However, the psychological effects of TOP for a fetal anomaly in women are not well documented in the literature.

We aimed to evaluate and compare the psychological effects of TOP for a fetal anomaly in women who underwent TOP in the first and second trimester of pregnancy.

\section{Material and Method}

This prospective cohort study was conducted between January-April 2020 in the Van Education and Research Hospital and Van Yuzuncu Yil University Faculty of Medicine. Women who underwent TOP for fetal anomaly were subdivided into two categories based on gestational age at TOP: First-trimester group, which was defined as TOP performed $<14$ weeks of gestation, and Second-trimester TOP who underwent TOP between 20 and 28 weeks of pregnancy. We determined 20 weeks as the lowest threshold for this group because, after 20 weeks, fetal movement can be felt by many women, and feticide is performed in the majority of TOP cases. Women who had a psychiatric disease and who are illiterate are excluded. The ethical committee of hospitals approved the study design and informed consent of all participants was received.

The decision to offer TOP was achieved by the consensus of three physicians. Neonatal morbidities and probability of mortality associated with fetal anomaly were explained to couples in detail. In the first-trimester group, TOP was performed by cervical evacuation of fetus following cervical dilatation with misoprostol. In the second-trimester group, feticide was applied to all of the women. Feticide was performed by a perinatology specialist (G.T) in all cases. After the aspiration of fetal blood to confirm the needle's correct placement, 3-5 $\mathrm{ml}$ strong (15\%) potassium chloride was injected into the fetal cardiac ventricle. Asystole was documented for at least 2 minutes, and a scan repeated after 30-60 minutes to ensure fetal demise. Induction of labor was performed following feticide with misoprostol or dinoprostone ovule.

Eight weeks after the TOP, women were invited to the hospital, and face to face interview was carried out. Entire interviews were performed by a psychiatrist (Y.S.A). Firstly, the social, demographic, and obstetric conditions of women were recorded. Subsequently, three questionnaires that measure psychological symptoms consisted of the interview: 1: Turkish validated version of the 21-item Beck Depression Inventory (BDI) $(4,5), 2$ : Turkish approved version of the 33- item Perinatal Grief Scale-short version (PGS) $(6,7)$, and 3: Turkish validated version of the 22-item Impact of Event Scale-Revised (IES-R) $(6,7)$. These self-completion questionnaires are highly validated for use in outpatient or community populations. BDI is one of the most widely used psychometric tests for measuring the severity of depression. Items receive a rating of zero to three to reflect their intensity and are summed linearly to create a score that ranges from 0 to 63 . The sum score of $\geq 10$ was defined as depression. PGS is particularly adapted for use in this population and measures the grief after perinatal loss. It is a simple test and has good validity and reliability. The short version has 33 items, and answers vary from 1 (strongly agree) to 5 (strongly disagree). The sum of scale ranges from 33 to 165 , and a value above 90 is defined as a psychiatric disease. The IES-R assesses subjective distress caused by traumatic events. Items are rated on a 5 -point scale ranging from 0 (not at all) to 4 (extremely). The IES yields a total score (ranging from 0 to 88 ), and a score of $\geq 26$ was determined as a post-traumatic stress disorder.

Consent for using data was obtained for this retrospective study. The study was conducted in accordance with the Declaration of Helsinki. Ethics committee approval was obtained (Ethics committee approval number: 2020/16 date: 20.01.2020).

SPSS (Statistical Package for the Social Science, Chicago, IL, USA) 16.0 for Windows version was employed for statistical analysis. Student t-test and Chi-square tests were used to compare variables where appropriate. A $p$-value of $<0.05$ indicated a significant difference.

\section{Results}

Forty-three women were recruited for our study including 24 women in the first-trimester group and 19 women in the second-trimester group. The mean maternal age was $24.4 \pm 5.8$ years in the first-trimester group and $22.1 \pm 3.1$ years in the second-trimester group, with no significant difference between the groups $(p=0.078)$. The mean gestational age at TOP was $12.1 \pm 2.1$ weeks in the first-trimester group and $25.2 \pm 2.4$ weeks in the second-trimester group $(p<0.01)$. The demographic and obstetric features of the two groups are summarized in table I.

The mean BDI score was $7.3 \pm 4.2$ in the first-trimester group and $11.1 \pm 4.6$ in the second-trimester group, and it was significantly higher in the second-trimester group $(p=0.033)$. Depression was detected in $29.1 \%$ of women in the firsttrimester group and $57.8 \%$ in the second-trimester group. The depression rate was significantly higher in the women who underwent TOP in the second-trimester $(p=0.023)$. The mean PGS score was $86.3 \pm 17.2$ in the first-trimester group and $101.4 \pm 29.2$ in the second-trimester group $(p=0.014)$. Perinatal grief was revealed in $45.8 \%$ and $84.2 \%$ of the women in the first and second-trimester groups, respectively. It was signifi- 
cantly higher in the group with second-trimester TOP $(p<0.01)$. IES-R scores of the first trimester and secondtrimester groups were $22.5 \pm 8.6$ and $35.3 \pm 17.1$, respectively $(p=0.022)$. Post-traumatic stress was detected in $41.6 \%$ of the first trimester and $73.6 \%$ of second-trimester groups. It was significantly higher in the second-trimester group $(p=0.031)$. The comparisons of the two groups, according to questionnaires, are shown in table II and table III.

Table I: Demographic and obstetric features of 43 women who underwent termination of pregnancy for fetal anomaly

\begin{tabular}{|c|c|c|c|}
\hline Variable & $\begin{array}{l}\text { 1. trimester } \\
n=24 \\
\text { Mean } \pm S D \text { or } n(\%)\end{array}$ & $\begin{array}{c}\text { 2. trimester } \\
n=19(\%) \\
\text { Mean } \pm \text { SD or } n(\%)\end{array}$ & $p$ \\
\hline \multirow[t]{2}{*}{ Age (years) } & $\begin{array}{l}\text { 1. trimester } \\
\mathrm{n}=24 \\
\text { Mean } \pm \text { SD or } \mathrm{n}(\%)\end{array}$ & $22.1 \pm 3.1$ & \multirow[t]{2}{*}{0.078} \\
\hline & Primary school: 19 (79.2) & Primary school: 13 (68.4) & \\
\hline Education & $\begin{array}{l}\text { High school: } 4 \text { (16.6) } \\
\text { University: } 1(4.2) \\
\text { Yes: } 7 \text { (29.1) }\end{array}$ & $\begin{array}{l}\text { High school: } 4 \text { (21.1) } \\
\text { University: } 2 \text { (10.5) } \\
\text { Yes: } 8 \text { (42.2) }\end{array}$ & 0.057 \\
\hline Job & No: 17 (70.9) & No: $11(57.8)$ & 0.024 \\
\hline Income & $\begin{array}{l}\text { Low: } 23 \text { (95.8) } \\
\text { Normal: } 1 \text { (4.2) }\end{array}$ & $\begin{array}{l}\text { Low: } 19 \text { (100) } \\
\text { Normal: } 0\end{array}$ & 0.089 \\
\hline Gestational age at TOP (weeks) & $\begin{array}{l}12.1 \pm 2.1 \\
\text { Anencephaly: } 15(62.5) \\
\text { Body stalk anomaly: } 1(4.2)\end{array}$ & $\begin{array}{l}25.2 \pm 2.4 \\
\text { Anencephaly: } 1(5.3) \\
\text { NTD: } 7(36.8) \\
\text { Cardiac anomaly } 3(15.8)\end{array}$ & $<0.01$ \\
\hline \multirow[t]{2}{*}{ Anomaly } & $\begin{array}{l}\text { Alobar holoprosencephaly: } 1 \text { (4.2) } \\
\text { Hydrops fetalis: } 5 \text { (20.7) }\end{array}$ & $\begin{array}{l}\text { Cardiac anomaly: } 3(15.8) \\
\text { Hydrops fetalis: } 3 \text { (15.8) } \\
\text { Bilateral renal agenesis: } 1 \text { (5.3) } \\
\text { Multiple anomalies: } 4 \text { (21) }\end{array}$ & NS \\
\hline & $\begin{array}{l}\text { Yes: } 18(75) \\
\text { No: } 6(25)\end{array}$ & $\begin{array}{l}\text { Yes:13 (68.4) } \\
\text { No: } 6(31.6)\end{array}$ & 0.067 \\
\hline Partner support & $\begin{array}{l}\text { Yes: } 20 \text { (83.3) } \\
\text { No: } 4 \text { (16.7) }\end{array}$ & $\begin{array}{l}\text { Yes: } 17 \text { (89.5) } \\
\text { No: } 2(10.5)\end{array}$ & 0.081 \\
\hline
\end{tabular}

Income: Low <7000 Turkish liras, Normal $\geq 7000$ Turkish liras, NTD: Neural tube defects, TOP: termination of pregnancy

Table II: Comparison of questionnaire scores in two groups

\begin{tabular}{lccc}
\hline Questionnaire & 1. Trimester & 2. trimester & $\mathrm{n}=19$ \\
& $\mathrm{n}=24$ & Mean \pm SD & $p$ \\
\hline Dean \pm SD & $7.3 \pm 4.2$ & $11.1 \pm 4.6$ & 0.033 \\
Grief (PGS) & $86.3 \pm 17.2$ & $101.4 \pm 29.2$ & 0.014 \\
Post-traumatic stress (IES-R) & $22.5 \pm 8.6$ & $35.3 \pm 17.1$ & 0.022 \\
\hline
\end{tabular}

BDI: Beck Depression Inventory, PGS: Perinatal grief scale-short version, IES-R: Impact of Event Scale-Revised

Table III: Comparison of psychiatric morbidities in two groups

\begin{tabular}{lccc}
\hline Psychopathology & 1. Trimester & 2. trimester & $p$ \\
& $\mathrm{n}=24, \mathrm{n}(\%)$ & $\mathrm{n}=19, \mathrm{n}(\%)$ & 0.023 \\
\hline Depression (BDI) & $7(29.1)$ & $11(57.8)$ & $<0.01$ \\
Grief (PGS) & $11(45.8)$ & $16(84.2)$ & 0.031 \\
Post-traumatic stress (IES-R) & $10(41.6)$ & $14(73.6)$ &
\end{tabular}

BDI: Beck depression inventory, PGS: Perinatal grief scale-short version, IES-R: Impact of Event Scale-Revised 


\section{Discussion}

Our study suggested that TOP for fetal anomaly causes numerous psychological morbidities such as depression, grief, and post-traumatic stress, eight weeks after the TOP. These morbidities are significantly prevalent in women who underwent TOP in the second trimester of pregnancy compared to first-trimester patients. Several factors may affect these results. A higher rate of depression, grief, and post-traumatic stress in the second-trimester group may be associated with a longer pregnancy duration. After 20 weeks of gestation, the majority of women feel fetal movements, and this feeling provides stronger maternal-fetal attachment. Also, solely feticide procedure may lead to extra psychological trauma in addition to TOP and alter the process of coping.

Women generally consider that the ultrasound examination always describes the health of a fetus, and therefore they are not prepared for malformations to be detected. Once a diagnosis of fetal anomaly has been confirmed, couples are confronted with deciding whether to continue or terminate the pregnancy. Various individual, social and obstetric factors such as lack of social support, absence of living children, pre-existence of psychiatric diseases, and the type and gestational weeks at diagnosis of fetal anomaly influence maternal reactions.

There are numerous papers in the literature that evaluate psychological consequences after TOP for fetal anomaly. The main difference between these studies is the method for the measurement of reactions after TOP. Some studies assessed women's perceptions via interviews qualitatively, including personal impressions about TOP. In contrast, the others used objective questionnaires to assess psychological influences quantitatively. Davies et al. evaluated 30 women with BDI, PGS, and IES-R., including 14 who had a first trimester TOP and 16 who had a second-trimester TOP for fetal anomaly. They showed that depression, grief, and post-traumatic stress were 4.7, 4.2, and 9.3 times more evident in the secondtrimester group than in first trimester women (10). Korenromp et al. evaluated 147 women 4, 8, and 16 months after TOP, using PGS and IES-R. They showed that psychological consequences continue in $20 \%$ of women up to $>1$ year. Low self-efficacy, high level of doubt during decision making, lack of partner support, being religious, and advanced gestational age were the most important predictors of the negative outcome (11).

Maguire et al. evaluated factors that contribute to and alleviate grief associated with TOP for fetal anomaly qualitatively and how that grief changes in 1 year. They performed three interviews with 11 women. Themes that contributed to grief included self-blame for the diagnosis, guilt around the termination decision, and social isolation related to discomfort with abortion. They found that self-blame was an early manifestation of grief, with women's feeling responsible for the anomaly. Participants experienced guilt concerning their pain and described feeling overwhelmed by having to decide to terminate a desired pregnancy. Also, women endorsed feeling abnormal and unable to talk about their loss. They emphasized that efforts to decrease abortion stigma, connect women to appropriate support networks, and develop pre-and post-procedure tools may improve women's grief and ultimately improve their emotional recovery (12). Kamranpour analyzed 40 women who underwent TOP after diagnosis of fetal anomaly qualitatively. They showed that women were shocked and had disbelief after being informed of the fetal anomaly. They experienced fear, anxiety, and depression after TOP. An inadequate and short timing counseling about the possible causes of fetal abnormalities has led to a feeling of guilt and self-blame (13).

A detailed but simplified briefing is crucial for couples in case of diagnosed fetal anomaly. Incorrect information may cause misleading and a waste of time. Asplin et al. evaluated 27 women's experiences after they received information on a detected fetal abnormality in pregnancy. Sixteen of those women continued their pregnancy, and 11 terminated. They performed interviews and evaluated psychological effects with basic questions like "how did you understand and feel about the information?". They revealed that many women consider that the information given at the first detecting ultrasound scan was uncertain and confusing. They concluded that to prevent confusion, uncertainty, and unnecessary anxiety, the women, asked for explicit and pedagogically presented information and demand information from different specialists (14).

One of the strongest points of our study was a homogenous patient selection. There was no significant difference between the two groups regarding demographic features. We conducted this study at a public hospital in a less developed region of the country. The majority of our patients were from low educated and low-income populations. We performed three objective useful, validated questionnaires instead of subjective interviews. We analyzed depression, grief, and posttraumatic stress quantitatively and objectively. To our knowledge, this is the first study, which evaluates the psychological influences of TOP for a fetal anomaly in an underdeveloped region of our country. Nevertheless, our findings indicate that TOP for fetal anomaly causes severe psychiatric problems in most women. Depression, grief, and post-traumatic stress are more prominent in women who underwent TOP in the second trimester of pregnancy.

The current study had numerous limitations. First of all, a relatively small sample size reduced the accuracy of the results. The other weak point was including sole women instead of couples. The third disadvantage was the lack of applying questionnaires to the participants long after TOP, such as one year. Due to this shortcoming, we could not analyze the alterations of psychological morbidities over time.

In conclusion, our study suggests that TOP for fetal anomaly leads to a substantial impact, including depression, 
grief, and post-traumatic stress on mothers. Women who underwent TOP in the second trimester of pregnancy suffer more emotional reactions than those who underwent in the first trimester. Psychosocial support after TOP for fetal anomaly may reduce these morbidities and accelerate the recovery of women. Further research is necessary, and it is recommended that future studies focus on randomized controlled trials which reveal the effects of psychological support in the general population and high-risk subgroups.

Acknowledgments: None

Conflict of interest: The authors declare no conflict of interest.

Funding: None

Authors'contributions: TG: Interpreted the results and wrote the draft manuscript. Analyzed the data and reviewed the draft manuscript, EE: Interpreted the results and wrote the draft manuscript, AYZ: Interpreted the results and wrote the draft manuscript, Analyzed the data and reviewed the draft manuscript, TS: Conceived and designed the study. Analyzed the data and reviewed the draft manuscript.

\section{References}

1. Rahim tahliyesi ve sterilizasyon hizmetlerinin yürütülmesi ve denetlenmesine ilişkin tüzük. No: 2827, 24/5/1983. T.C. Sağlık Bakanlı̆̆ı.

2. ACOG. ACOG practice bulletin. Clinical management guidelines of obstetrician-gynecologists. Number 67, October 2005. Medical management of abortion. Obstet Gynecol. 2005;106(4):871-82. Doi:10.1097/00006250200510000-00051.

3. Charles VE, Polis CB, Sridhara SK, Blum RW. Abortion and long-term mental health outcomes: a systematic review of the evidence. Contraception. 2008;78(6):436-50. Doi:10.1016/j.contraception.2008.07.005.

4. Beck AT, Ward CH, Mendelson M, Mock J, Erbaugh J. An inventory for measuring depression. Arch Gen Psychiatry. 1961;4:561-71. Doi: 10.1001/archpsyc.1961. 01710120031004.

5. Aktürk Z, Dağdeviren N, Türe M, Tuğlu C. The reliability and validity analysis of the Turkish version of beck depression inventory for primary care. Türk Aile Hek Derg. 2005;9(3):117-22.
6. Potvin L, Lasker J, Toedter L. Measuring grief: a short version of the Perinatal Grief Scale. J Psychopathol Behav Asses. 1989;11:29-45. Doi:10.1007/BF00962697.

7. Köneş MÖ, Kaydırak MM, Aslan E, Yıldız H. The Perinatal Grief Scale (33-item short version): validity and reliability of the Turkish version. Anadolu Psikiyatri Derg. 2017;18(3):231-6. Doi:10.5455/apd.234509.

8. Weiss DS, Marmar CR. The impact of event scale-revised. In: J. Wilson J, Keane TM, editors. Assessing psychological trauma and PTSD. New York: Guilford;1997. p. 399411.

9. Çorapçıŏlu A, Yargıç I, Geyran P, Kocabaşoğlu N. "Olayların Etkisi Ölçeği” (IES-R) Türkçe versiyonunun geçerlilik ve güvenilirliği. New/Yeni Symposium Journal. 2006;44:14-8.

10. Davies V, Gledhill J, McFadyen A, Whitlow B, Economides D. Psychological outcome in women undergoing termination of pregnancy for ultrasound-detected fetal anomaly in the first and second trimesters: a pilot study. Ultrasound Obstet Gynecol. 2005;25(4):389-92. Doi:10.1002/uog.1854.

11. Korenromp MJ, Page-Christiaens GC, van den Bout J, Mulder EJ, Visser GH. Adjustment to termination of pregnancy for fetal anomaly: a longitudinal study in women at 4, 8, and 16 months. Am J Obstet Gynecol. 2009;201(2): 160.e1-160.e1607. Doi: 10.1016/j.ajog. 2009.04.007.

12. Maguire M, Light A, Kuppermann M, Dalton VK, Steinauer JE, Kerns JL. Grief after second-trimester termination for fetal anomaly: a qualitative study. Contraception. 2015;91(3):234-9. Doi:10.1016/j.contraception.2014.11.015.

13. Kamranpour B, Noroozi M, Bahrami M. Psychological experiences of women with pregnancy termination due to fetal anomalies: a qualitative study from the perspective of women, their spouses, and healthcare providers in Iran. Reprod Health. 2020;17(1):109. Doi:10.1186/s12978020-00959-y.

14. Asplin N, Wessel H, Marions L, Georgsson Öhman S. Pregnant women's experiences, needs, and preferences regarding information about malformations detected by ultrasound scan. Sex Reprod Healthc. 2012;3(2):73-8. Doi: 10.1016/j.srhc.2011.12.002 